\title{
CONTROLE GENÉTICO DA EFICIÊNCIA DE UTILIZAÇÃO DE FÓSFORO EM FAMÍLIAS DE MEIOS-IRMÃOS DE Eucalyptus grandis, EM CASA DE VEGETAÇÃ̃ ${ }^{1}$
}

\author{
Rinaldo Cesar de Paula ${ }^{2}$, Nadia Figueiredo de Paula ${ }^{3}$, Sérgio Valiengo Valeri², Mara Cristina Pessôa da $\mathrm{Cruz}^{4}$ e \\ Ana Lídia Tonani Tolfo ${ }^{5}$
}

\begin{abstract}
RESUMO - Com o objetivo de avaliar a existência e a magnitude da variabilidade genética para a eficiência de utilização de fósforo, conduziu-se o experimento em casa de vegetação, usando 18 famílias de meios-irmãos de Eucalyptus grandis W. Hill ex Maiden, submetidas a três doses de fósforo $\left(0,200\right.$ e $400 \mathrm{mg} / \mathrm{dm}^{3}$ de $\left.\mathrm{P}_{2} \mathrm{O}_{5}\right)$. $\mathrm{O}$ experimento foi disposto em delineamento inteiramente casualizado, no esquema fatorial $18 \times 3$, num total de 54 tratamentos, com três repetições de duas plantas, e foi conduzido em vasos com $7 \mathrm{dm}^{3}$ de solo. Aos 120 dias após o transplantio das mudas, foram avaliados a altura e o diâmetro do coleto; a massa seca de raízes, caule, galhos, folhas, parte aérea e total, a relação raiz-parte aérea; e o teor, o conteúdo e a eficiência de utilização de fósforo nas folhas e no caule das plantas. As famílias responderam positivamente à adubação fosfatada, porém de forma diferenciada para cada característica, apresentando tendência de estabilização na maior dose testada. A adição de $400 \mathrm{mg} / \mathrm{dm}^{3}$ de $\mathrm{P}_{2} \mathrm{O}_{5}$ causou maior absorção de $\mathrm{P}$, porém não proporcionou a maior produção de matéria seca, resultando em menor eficiência de utilização de P nesta condição. Em geral, o material testado apresentou baixa variabilidade genética, mas foi possível identificar materiais promissores para as características avaliadas.
\end{abstract}

Palavras-chave: Melhoramento florestal, nutrição florestal e eficiência nutricional.

\section{GENETIC CONTROL OF PHOSPHORUS UTILIZATION EFFICIENCY IN HALF-SIB FAMILIES OF Eucalyptus grandis, UNDER GREENHOUSE CONDITIONS}

\begin{abstract}
A greenhouse experiment was carried out to evaluate the genetic variability in the efficiency of phosphorus utilization in 18 half-sib families of Eucalyptus grandis W. Hill ex Maiden, submitted to three phosphorus levels $\left(0,200\right.$ and $400 \mathrm{mg} / \mathrm{dm}^{3} \mathrm{P}_{2} \mathrm{O}_{5}$ ). The experiment was arranged in a completely randomized design, following an $18 \times 3$ factorial scheme totaling 54 treatments and three replications of two plants per pot, containing $7 \mathrm{dm}^{3}$ of soil grown until 120 days after transplant. Height, collar diameter; and dry matter of roots, stems, branches, leaves, shoots and total dry matter, shoot-root rate and P concentration, content and utilization efficiency in the leaves and in the stems were evaluated. The families responded positively to fertilization, differently for each characteristic, with a tendency to stabilize at the highest level. The highest P absorption was observed when $400 \mathrm{mg} / \mathrm{dm}^{3} \mathrm{P}_{2} \mathrm{O}_{5}$ were added. However, this was not accompanied by increased dry matter production, resulting in lower P utilization efficiency under this condition. In general, the genetic material evaluated presented low genetic variability, but it was possible to identify promising materials for the characteristics evaluated.
\end{abstract}

Key words: Forest improvement, forest nutrition and nutritional efficiency.

\section{INTRODUÇÃO}

Na Austrália, o Eucalyptus grandis ocorre, predominantemente, em áreas de baixada ou em partes mais baixas de vales com solos supostamente mais férteis, profundos e bem drenados ( Barros et al., 1990). Para estes autores, em princípio, tal espécie não teria razões para desenvolver um sistema de armazenamento de nutrientes, o que resultaria em alta eficiência de utilização de nutrientes. Em trabalho realizado por Silva et al. (1983),

1 Recebido para publicação em 12.6.2001.

Aceito para publicação em 19.2.2003.

2 Prof. do Departamento de Produção Vegetal da FCAV/UNESP, Campus de Jaboticabal, 14884-900 Jaboticabal-SP, $<$ rcpaula@fcav.unesp.br>; ${ }^{3}$ Doutoranda da UFSCar, PPG-ERN, São Carlos-SP; ${ }^{4}$ Prof ${ }^{a}$. do Departamento de Solos e Adubos da FCAV/UNESP; ${ }^{5}$ Mestranda do Programa de Genética e Melhoramento de Plantas da FCAV/UNESP. 
o E. grandis, comparado com E. saligna, E. propinqua, E. dunnii e E. robusta, foi a espécie mais eficiente na utilização de fósforo, proporcionando uma produção de $43.441 \mathrm{~kg}$ de biomassa do lenho por quilograma de fósforo neste componente. Todavia, Barros et al. (1990) citaram estudos em condições de campo em que o E. grandis, origem Atherton, mostrou-se menos eficiente nutricionalmente, por exemplo, que o E. cloeziana, origem Helen Valtey, ressaltando que no estádio de mudas ele apresentou maior reserva de fósforo inorgânico nos vacúolos do que o E. camaldulensis. Por isto, há grande interesse em estudar o controle genético da eficiência de utilização de nutrientes para essa espécie.

Guimarães (1993) relatou que diferenças inerentes à absorção de nutrientes e à resposta em crescimento ocorrem entre espécies, procedências, progênies e clones de espécies florestais, e preconizou que genótipos que crescem bem em solos de baixa fertilidade devem ser selecionados, sendo desejáveis aqueles que tenham menores necessidades nutricionais, sem, contudo, comprometer a produtividade. Assim, o entendimento do grau de variabilidade genética sobre atributos nutricionais e fisiológicos do crescimento de plantas é fundamental para a seleção e o melhoramento mais eficientes e, conseqüentemente, para o aumento do ganho genético, com menor impacto sobre o nível de nutrientes do solo.

As estimativas de herdabilidade para as principais características morfológicas e fisiológicas que podem afetar a eficiência de utilização de nutrientes demonstram que essas possuem altos valores, o que evidencia o forte controle genético sobre elas (Nambiar et al., 1982). Desta forma, o presente trabalho teve por objetivos avaliar a variabilidade genética entre famílias de meios-irmãos de Eucalyptus grandis e estimar parâmetros genéticos para características de crescimento e de eficiência de utilização de fósforo.

\section{MATERIAL E MÉTODOS}

Foi instalado um ensaio que envolveu 18 famílias de meios-irmãos de Eucalyptus grandis W. Hill ex Maiden, conduzido em casa de vegetação, no Viveiro Experimental de Plantas Ornamentais e Florestais da Faculdade de Ciências Agrárias e Veterinárias/UNESP, Campus de Jaboticabal.

As sementes foram postas para germinar em bandejas de plástico, usando areia de rio esterilizada como substrato para germinação. Sessenta dias após a semeadura, as plântulas foram transplantadas para os recipientes definitivos, contendo como substrato solo coletado na camada de 20 a $40 \mathrm{~cm}$, cuja caracterização físico-química encontra-se no Quadro 1. A este substrato aplicou-se a seguinte adubação básica: $30 \mathrm{mg} / \mathrm{dm}^{3} \mathrm{de} \mathrm{N}$; $200 \mathrm{mg} / \mathrm{dm}^{3}$ de $\mathrm{K}_{2} \mathrm{O} ; 30 \mathrm{mg} / \mathrm{dm}^{3}$ de $\mathrm{S} ; 5 \mathrm{mg} / \mathrm{dm}^{3}$ de $\mathrm{Zn}$; $0,5 \mathrm{mg} / \mathrm{dm}^{3}$ de B; $0,5 \mathrm{mg} / \mathrm{dm}^{3}$ de $\mathrm{Cu} ; 1,5 \mathrm{mg} / \mathrm{dm}^{3}$ de $\mathrm{Mn}$; e $0,1 \mathrm{mg} / \mathrm{dm}^{3}$ de Mo. A calagem foi realizada de forma a elevar a porcentagem de saturação por bases para $60 \%$, utilizando a relação 3:1 de $\mathrm{Ca}: \mathrm{Mg}, 20$ dias antes do transplante das mudas. Os níveis de fósforo corresponderam à não-adição ou à adição de $200 \mathrm{ou} 400 \mathrm{mg} / \mathrm{dm}^{3} \mathrm{de} \mathrm{P}_{2} \mathrm{O}_{5}$, na forma de superfosfato triplo, aplicados em uma única vez, juntamente com os corretivos de acidez e incorporados manualmente ao solo. Quarenta dias após o transplantio foram aplicados $30 \mathrm{mg} / \mathrm{dm}^{3}$ de $\mathrm{N}$, como sulfato de amônio, em cobertura.

Quadro 1 - Características físicas e químicas do solo utilizado no experimento

Table 1 - Physical and chemical characteristics of the soil utilized in the experiment

\begin{tabular}{|c|c|c|c|c|c|c|c|c|c|}
\hline \multicolumn{10}{|c|}{ Característica Química } \\
\hline \multirow{2}{*}{$\frac{\mathrm{pH}}{\left(\mathrm{CaCl}_{2}\right)}$} & \multirow{2}{*}{$\frac{\mathrm{MO}}{\left(\mathrm{g} / \mathrm{dm}^{3}\right)}$} & \multirow{2}{*}{$\begin{array}{l}\text { P (resina) } \\
\left(\mathrm{mg} / \mathrm{dm}^{3}\right) \\
\end{array}$} & $\mathrm{K}$ & $\mathrm{Ca}$ & $\mathrm{Mg}$ & $\mathrm{H}+\mathrm{Al}$ & SB & $\mathrm{T}$ & $\mathrm{V}$ \\
\hline & & & \multicolumn{6}{|c|}{$\left(\mathrm{mmol}_{\mathrm{c}} / \mathrm{dm}^{3}\right)$} & $(\%)$ \\
\hline 4,6 & 1 & 1 & 0,8 & 6 & 2 & 16 & 9 & 25 & 35 \\
\hline \multicolumn{10}{|c|}{ Característica Granulométrica } \\
\hline \multirow[b]{2}{*}{ Argila } & \multirow[b]{2}{*}{ Limo } & \multicolumn{7}{|c|}{ Areia } & \multirow{2}{*}{$\begin{array}{l}\text { Classe } \\
\text { Textural }\end{array}$} \\
\hline & & Muito Fina & Fina & Média & Grossa & & & Total & \\
\hline \multicolumn{9}{|c|}{$(\mathrm{g} / \mathrm{kg})$} & \multirow{2}{*}{ Argilosa } \\
\hline 390 & 60 & 110 & 310 & 110 & 20 & & & 550 & \\
\hline
\end{tabular}

R. Árvore, Viçosa-MG, v.27, n.1, p.25-34, 2003 
$\mathrm{O}$ experimento foi disposto em delineamento inteiramente casualizado, segundo um esquema fatorial $18 \times 3$ (18 famílias de meios-irmãos e três níveis de adubação fosfatada), perfazendo um total de 54 tratamentos, com três repetições. Cada unidade experimental foi composta por dois vasos, contendo $7 \mathrm{dm}^{3}$ de solo e duas plantas. Para análise de variância, utilizou-se a média das parcelas.

Aos 120 dias após o transplantio das mudas para os recipientes definitivos, foram avaliados o crescimento em altura (ALT) e o diâmetro do coleto (DC) das plantas e procedeu-se à coleta dos componentes da planta para determinação da massa seca e da concentração de P nas folhas e no caule. A massa seca de raízes (MSR), do caule (MSC), dos galhos (MSG), das folhas (MSF), da parte aérea (MSPA $=$ MSC + MSG + MSF) e total $($ MST $=$ MSPA + MSR) e a relação raiz-parte áerea (RPA) foram obtidas após submeter o material vegetal à secagem em estufa de ventilação forçada, a $65 \pm 5^{\circ} \mathrm{C}$, por 96 horas. Após secagem, o material vegetal foi pesado, moído e digerido por uma mistura nitricoperclórica, para determinação posterior da concentração de $\mathrm{P}$ nas folhas (TPF) e no caule (TPC), por colorimetria (A.O.A.C., 1975). As análises químicas foram realizadas no Laboratório de Pós-colheita de Produtos Hortícolas do Departamento de Produção Vegetal da FCAV/UNESP, Jaboticabal-SP.

Os conteúdos de $\mathrm{P}$ nas folhas (CPF) e no caule (CPC) foram obtidos ao multiplicar os respectivos valores de massa seca pela concentração de P. A eficiência de utilização de fósforo nas folhas (EUPF) e no caule (EUPC) foi determinada por meio da metodologia proposta por Siddiqi \& Glass (1981), ou seja,

$E U P($ nas folhas ou no caule $)=\frac{[\text { Biomassa }(\text { de folhas ou caule })]^{2}}{\text { Conteúdo de } P(\text { nas folhas ou no caule })}$

\section{RESULTADOS E DISCUSSÃO}

\subsection{Características de Crescimento e de Produção de Matéria Seca}

As plantas que não receberam fósforo adicional tiveram seu crescimento seriamente comprometido (Quadro 2), o que evidencia que o fósforo é um nutriente indispensável ao crescimento inicial do eucalipto. Segundo Barros et al. (1990), por causa da baixa disponibilidade de $\mathrm{P}$ nos solos e subsolos freqüentemente utilizados para produção de mudas de eucalipto, muitas vezes, quando não é aplicado $\mathrm{P}$ ao substrato, as mudas nem mesmo crescem.

Segundo Raij et al. (1997), o teor inicial de P no solo é muito baixo (Quadro 1). Novais et al. (1990) relataram que, quando o solo apresenta baixo teor de $\mathrm{P}$, espera-se resposta acentuada do eucalipto à aplicação deste elemento, tanto na fase de produção de mudas como de estabelecimento das plantas no campo. Tal fato foi verificado para todas as características avaliadas, em menor grandeza para crescimento em altura e em diâmetro e, de maneira mais significativa, para produção de matéria seca. Apenas a relação raiz-parte aérea (RPA) diminuiu com o aumento das doses de $\mathrm{P}$, indicando que em condições subótimas de crescimento a planta destina maior potencial de crescimento para o sistema radicular em detrimento da parte aérea, o que concorda com as argumentações de Barros et al. (1990), Reis et al. (1994) e Braga et al. (1995). Segundo Clarkson (1985), o maior crescimento das raízes em relação à parte aérea é uma estratégia da planta para retirar o máximo de nutrientes do solo, em condição de baixa fertilidade.

$\mathrm{O}$ acréscimo em todas as características, quando se aumentou a dose de 200 para $400 \mathrm{mg} / \mathrm{dm}^{3}$ de $\mathrm{P}_{2} \mathrm{O}_{5}$, foi menor do que de 0 para $200 \mathrm{mg} / \mathrm{dm}^{3}$ de $\mathrm{P}_{2} \mathrm{O}_{5}$, o que evidencia a estabilização do crescimento nesta última condição. Em termos proporcionais, a alocação de biomassa em resposta à adubação fosfatada sofreu alteração apenas em relação às plantas não-adubadas, mantendo-se praticamente inalterada quando foram aplicados $200 \mathrm{ou}$ $400 \mathrm{mg} / \mathrm{dm}^{3}$ de $\mathrm{P}_{2} \mathrm{O}_{5}$ (Quadro 2). Ao aplicar fósforo, houve redução na participação de raízes e galhos na matéria seca total e aumento da participação de folhas e caule. Furtini Neto et al. (1996) relataram que para obter $90 \%$ da máxima produção de matéria seca de cinco espécies de eucalipto (E. cloeziana, E. grandis, E. pellita, E. pilularis e E. urophylla) as doses de $\mathrm{P}$ variaram entre 220,2 e $254,8 \mathrm{mg} / \mathrm{kg}$ de P, de acordo com cada uma das espécies, e que entre estas o $E$. grandis foi a mais exigente em $P$, sendo considerada de inadequado estabelecimento em solos pobres em $\mathrm{P}$, mas com resposta acentuada à aplicação deste nutriente.

O comportamento médio das famílias para as características de crescimento e de produção pode ser visualizado no Quadro 3. A diferença porcentual entre as famílias de desempenho superior e as de desempenho inferior foi de $56,63 \%$ para a MSC, $51,85 \%$ para o MSR, 38,53\% para o MSG e 26,60, 31,40 e 43,34\% para MST, MSPA

R. Árvore, Viçosa-MG, v.27, n.1, p.25-34, 2003 
Quadro 2 - Estimativas de parâmetros genético-estatísticos e desempenho médio de plantas de 18 famílias de meiosirmãos de Eucalyptus grandis submetidas a três níveis de adubação fosfatada, aos 120 dias de idade em casa de vegetação

Table 2 - Estimates of genetic and statistical parameters and average performance of plants of 18 Eucalytpus grandis half-sib families, submitted to three phosphorus levels, 120 days after transplant under greenhouse conditions

\begin{tabular}{|c|c|c|c|c|c|c|c|c|c|}
\hline & ALT & $\mathrm{DC}$ & MSR & MSC & MSG & MSF & MSPA & MST & RPA \\
\hline & $(\mathrm{cm})$ & $(\mathrm{mm})$ & \multicolumn{7}{|c|}{ (g) } \\
\hline & \multicolumn{9}{|c|}{ Valores de F } \\
\hline Adubação (A) & $513,78 * *$ & $1.454,72 * *$ & $664,28 * *$ & $556,15^{* *}$ & $1.219,57 * *$ & $703,59 * *$ & $1.308,70^{* *}$ & $1.654,70 * *$ & $41,79 * *$ \\
\hline Famílias (F) & $2,12 * *$ & $2,72 * *$ & $1,78^{\text {ns }}$ & $1,24^{\mathrm{ns}}$ & $1,81^{\mathrm{ns}}$ & $1,97^{*}$ & $1,65^{\mathrm{ns}}$ & $1,75^{\mathrm{ns}}$ & $0,77^{\mathrm{ns}}$ \\
\hline \multirow[t]{2}{*}{$\mathrm{A} \times \mathrm{F}$} & $1,32^{\mathrm{ns}}$ & $1,05^{\mathrm{ns}}$ & $1,11^{\mathrm{ns}}$ & $1,12^{\mathrm{ns}}$ & $1,40^{\mathrm{ns}}$ & $1,10^{\mathrm{ns}}$ & $1,06^{\mathrm{ns}}$ & $0,83^{\text {ns }}$ & $1,14^{\mathrm{ns}}$ \\
\hline & \multicolumn{9}{|c|}{ Estimativas de parâmetros genético-estatísticos } \\
\hline Média & 83,19 & 8,32 & 27,056 & 19,696 & 10,989 & 29,855 & 60,328 & 87,038 & 0,565 \\
\hline $\mathrm{CV}(\%)$ & 16,62 & 11,97 & 21,73 & 24,32 & 14,30 & 21,80 & 16,36 & 16,26 & 36,95 \\
\hline $\mathrm{CV}_{\mathrm{P}}$ & 6,73 & 5,36 & 6,76 & 4,21 & 5,07 & 7,51 & 4,53 & 4,27 & 0,00 \\
\hline $\mathrm{CV}_{\mathrm{Fm}}$ & 9,26 & 6,74 & 10,20 & 9,54 & 7,58 & 10,71 & 7,21 & 6,90 & 13,15 \\
\hline $\mathrm{h}_{\mathrm{m}}^{2}$ & 0,53 & 0,63 & 0,44 & 0,19 & 0,45 & 0,49 & 0,40 & 0,38 & - \\
\hline $\mathrm{mg} / \mathrm{dm}^{3}$ de $\mathrm{P}_{2} \mathrm{O}_{5}$ & \multicolumn{9}{|c|}{ Desempenho médio } \\
\hline 0 & 26,65 & 2,22 & 2,057 & 1,027 & 0,847 & 1,559 & 3,046 & 5,084 & 0,791 \\
\hline 200 & 109,26 & 11,08 & 37,560 & 27,564 & 15,062 & 41,025 & 83,401 & 119,946 & 0,456 \\
\hline 400 & 113,65 & 11,66 & 41,549 & 30,496 & 17,058 & 46,980 & 94,535 & 136,084 & 0,447 \\
\hline
\end{tabular}

** - significativo a $1 \%$ de probabilidade; $* \mathrm{e}^{\mathrm{ns}}$ - significativo e não-significativo a $5 \%$ de probabilidade, respectivamente.

ALT - altura, DC - diâmetro do coleto, MSR - matéria seca de raízes, MSC - matéria seca de caule, MSG - matéria seca de galhos, MSF matéria seca de folhas, MSPA - matéria seca da parte aérea, MST - matéria seca total, RPA - relação raiz-parte aérea. Estimativas dos coeficientes de variação genética $\left(\mathrm{CV}_{\mathrm{p}}\right)$, fenotípica em nível de média de famílias $\left(\mathrm{CV}_{\mathrm{Fm}}\right)$, do coeficiente de variação experimental $(\mathrm{CV})$ e do coeficiente de herdabilidade em nível de média de famílias $\left(\mathrm{h}^{2}{ }_{\mathrm{m}}\right)$.

e RPA, respectivamente. Para as características em que foi detectada variabilidade genética esta diferença foi de $42,62 \%$ para MSF, $49,82 \%$ para ALT e de $24,42 \%$ para DC.

À exceção da MSC, cuja estimativa de herdabilidade pode ser considerada baixa, e da RPA, com valor nulo, as demais características apresentaram-se sob moderado controle genético. As estimativas dos coeficientes de variação genética e fenotípica encontram-se dentro dos padrões citados na literatura, em trabalhos semelhantes (Guimarães, 1995; Paula et al., 1996).

A resposta à adubação foi diferenciada entre as famílias para cada característica (Quadro 4). Neste sentido, verifica-se que as características altura e diâmetro do coleto não seguem, necessariamente, a tendência verificada para as características de produção de matéria seca. Contudo, houve resposta acentuada das famílias à adubação, para todas as características, quando estas receberam $200 \mathrm{mg} / \mathrm{dm}^{3}$ de $\mathrm{P}_{2} \mathrm{O}_{5}$. Algumas famílias continuaram respondendo positivamente à adubação quando submetidas a $400 \mathrm{mg} / \mathrm{dm}^{3} \mathrm{de}_{2} \mathrm{O}_{5}$, sendo, porém, este acréscimo de pequena magnitude, ao passo que outras apresentaram redução nas características avaliadas nesta condição. Este baixo incremento no crescimento quando as famílias foram submetidas a $400 \mathrm{mg} / \mathrm{dm}^{3}$ de $\mathrm{P}_{2} \mathrm{O}_{5}$ é um indicativo de que, em solos com características semelhantes ao utilizado no presente experimento, a adição de doses superiores a $200 \mathrm{mg} / \mathrm{dm}^{3}$ de $\mathrm{P}_{2} \mathrm{O}_{5}$ poderá não resultar em melhoria do desempenho das plantas.

Considerando que o desempenho em altura, o diâmetro do coleto, a massa seca de caule, a massa seca de folhas e a massa seca da parte aérea são as características mais importantes nesta fase de crescimento das plantas, e adotando-se uma seleção de $50 \%$ dos acessos estudados, as famílias 9, 3, 11, 1, 4, 18, 10, 6 e 5 são as eleitas por apresentarem os melhores desempenhos no conjunto destes caracteres. 
Quadro 3 - Crescimento em altura $(\mathrm{cm})$ e diâmetro do coleto $(\mathrm{mm})$ e produção de massa seca $(\mathrm{g} /$ planta) e relação raiz-parte aérea de 18 famílias de meios-irmãos de Eucalyptus grandis, aos 120 dias de idade em casa de vegetação

Table 3 - Growth $(\mathrm{cm})$ and collar diameter $(\mathrm{mm})$, dry matter production (g/plant) and root-shoot ratio of plants of 18 Eucalytpus grandis half-sib families, 120 days after transplant under greenhouse conditions

\begin{tabular}{|c|c|c|c|c|c|c|c|c|c|}
\hline Família & ALT & DC & MSR & MSC & MSG & MSF & MSPA & MST & RPA \\
\hline 1 & 85,36 & 8,50 & 26,32 & 19,86 & 10,80 & 31,37 & 61,86 & 88,18 & 0,535 \\
2 & 87,11 & 8,44 & 33,33 & 17,59 & 11,67 & 31,48 & 60,78 & 91,69 & 0,537 \\
3 & 90,30 & 8,51 & 26,91 & 20,18 & 11,50 & 33,48 & 65,05 & 89,55 & 0,643 \\
4 & 90,55 & 8,48 & 29,52 & 19,36 & 11,69 & 32,68 & 63,55 & 93,08 & 0,637 \\
5 & 84,22 & 9,00 & 26,55 & 21,36 & 11,44 & 29,04 & 61,21 & 87,64 & 0,561 \\
6 & 86,67 & 8,02 & 26,20 & 21,90 & 11,13 & 31,29 & 64,20 & 90,40 & 0,575 \\
7 & 80,11 & 7,93 & 28,52 & 20,12 & 11,29 & 27,23 & 58,61 & 87,13 & 0,486 \\
8 & 73,77 & 7,43 & 21,94 & 19,76 & 10,54 & 25,39 & 54,76 & 76,71 & 0,544 \\
9 & 102,58 & 9,07 & 24,87 & 23,62 & 10,84 & 32,39 & 66,70 & 91,58 & 0,476 \\
10 & 86,25 & 9,02 & 28,91 & 18,79 & 12,43 & 32,03 & 63,26 & 92,18 & 0,518 \\
11 & 85,33 & 8,74 & 25,94 & 21,26 & 9,98 & 32,52 & 63,70 & 89,65 & 0,498 \\
12 & 73,41 & 7,39 & 24,36 & 19,60 & 9,92 & 24,78 & 53,39 & 77,76 & 0,530 \\
13 & 77,22 & 8,25 & 29,39 & 18,73 & 10,99 & 30,55 & 60,18 & 87,95 & 0,674 \\
14 & 82,52 & 8,18 & 28,73 & 19,27 & 10,24 & 26,07 & 55,45 & 84,19 & 0,634 \\
15 & 78,55 & 8,56 & 28,50 & 15,07 & 10,96 & 31,77 & 60,75 & 89,26 & 0,604 \\
16 & 68,47 & 7,28 & 22,04 & 17,60 & 8,98 & 24,37 & 50,77 & 72,81 & 0,683 \\
17 & 80,00 & 8,03 & 28,34 & 19,38 & 11,33 & 27,58 & 58,40 & 86,74 & 0,521 \\
18 & 85,00 & 8,97 & 26,54 & 21,01 & 12,00 & 30,32 & 63,26 & 89,81 & 0,511 \\
\hline
\end{tabular}

ALT - altura, DC - diâmetro do coleto, MSR - matéria seca de raízes, MSC - matéria seca de caule, MSG - matéria seca de galhos, MSF matéria seca de folhas, MSPA - matéria seca da parte aérea, MST - matéria seca total e RPA - relação raiz-parte aérea.

\subsection{Teor, Conteúdo e Eficiência de Utilização de Fósforo}

O teor e o conteúdo de $\mathrm{P}$ nas folhas e no caule e a eficiência de utilização de $P$ nas folhas (EUPF) aumentaram com a dose de $\mathrm{P}$, havendo, porém, redução nas estimativas da eficiência de utilização de P no caule (EUPC) na maior dose aplicada (Quadro 5). Tal fato se deve a um aumento proporcionalmente maior no teor de $\mathrm{P}$ que na matéria seca do caule (Quadros 5 e 2). À exceção dos teores de P nas folhas (TPF) e no caule (TPC), as demais características apresentam $\mathrm{CV}$ alto a muito alto, de acordo com as considerações de Pimentel Gomes (1990).

As estimativas de herdabilidade, à exceção do TPF e da EUPC, que foram estatisticamente nulas, podem ser consideradas de magnitude moderada. Já as estimativas do $\mathrm{CV}_{\mathrm{Fm}}$ e $\mathrm{CV}_{\mathrm{p}}$ são de baixa magnitude, confirmando a baixa variabilidade genética no material em estudo.

Defrontando-se os resultados de teor e conteúdo de $\mathrm{P}$ nas folhas e no caule, pode-se constatar que, embora o teor de P na planta possa variar pouco de uma situação de baixa disponibilidade para uma de alta disponibilidade do elemento no solo, a quantidade total disponível do elemento para a planta é o que fará a diferença entre baixa e alta produtividade. Assim, a maior disponibilidade de $\mathrm{P}$, quando da aplicação de 200 ou $400 \mathrm{mg} / \mathrm{dm}^{3}$ de $\mathrm{P}_{2} \mathrm{O}_{5}$, foi a determinante da grande diferença de crescimento e de produção de massa seca observados quando as plantas não receberam fósforo adicional ou quando receberam as doses citadas.

Houve tendência de estabilização nos valores da EUPF quando foram aplicados 200 ou $400 \mathrm{mg}$ de $\mathrm{P}_{2} \mathrm{O}_{5}$ e para a EUPC constatou-se redução para o maior nível de adubação fosfatada. Estes resultados são justificados pelos maiores conteúdos de $\mathrm{P}$ nestes dois componentes, verificados para plantas submetidas ao maior nível de adubação, sem aumento simultâneo expressivo na matéria seca (Quadros 2 e 5). Este fato, segundo ponderações de Furtini Neto et al. (1996), caracteriza um possível consumo de luxo de $\mathrm{P}$ pelas plantas, na condição de alta disponibilidade deste elemento.

R. Árvore, Viçosa-MG, v.27, n.1, p.25-34, 2003 
PAULA, R.C. et al.

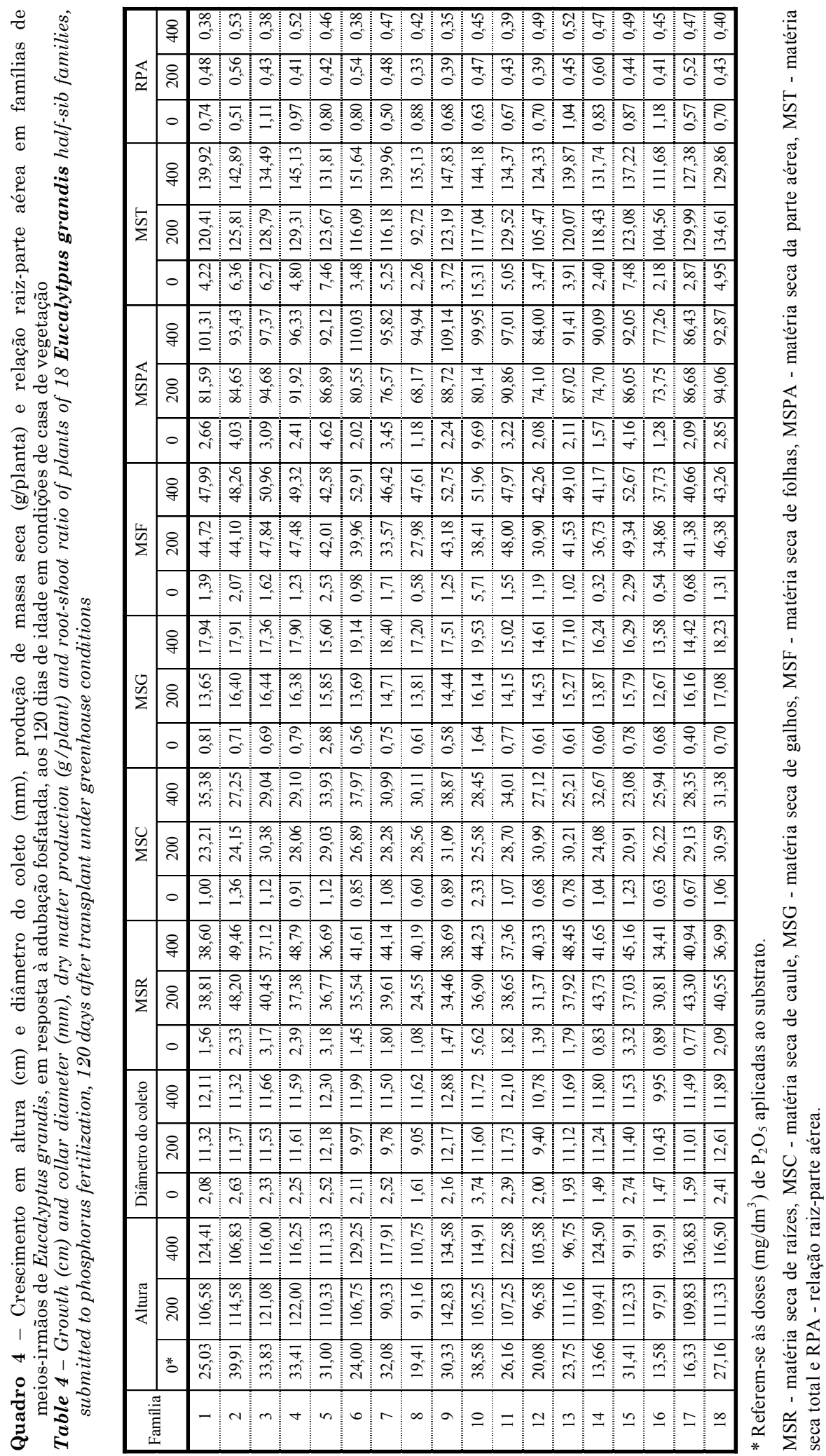


Quadro 5 - Estimativas de parâmetros genético-estatísticos e teor (g/kg), conteúdo (g) e eficiência de utilização de P nas folhas e no caule [(g de matéria seca) $)^{2} /(\mathrm{g}$ de $\left.\mathrm{P})\right]$ em famílias de meios-irmãos de Eucalyptus grandis aos 120 dias de idade, submetidas a três níveis de adubação fosfatada em casa de vegetação

Table 5 -Estimates of genetic and statistical parameters and concentration, content and efficiency of phosphorus utilization in the leaves and stem [( $g$ of dry matter $)^{2} /(g$ of $\left.P)\right]$ of plants of 18 Eucalytpus grandis half-sib families, submitted to three phosphorus levels, 120 days after transplant under greenhouse conditions

\begin{tabular}{|c|c|c|c|c|c|c|}
\hline & TPF & TPC & $\mathrm{CPF}$ & $\mathrm{CPC}$ & EUPF & EUPC \\
\hline & \multicolumn{6}{|c|}{ Valores de F } \\
\hline Adubação (A) & $11,22 * *$ & $927,75^{* *}$ & $772,70 * *$ & $608,09 * *$ & $550,09^{* *}$ & $190,09^{* *}$ \\
\hline Famílias (F) & $0,51^{\mathrm{ns}}$ & $1,48^{\mathrm{ns}}$ & $2,08^{*}$ & $1,47^{\mathrm{ns}}$ & $1,74^{\mathrm{ns}}$ & $0,74^{\mathrm{ns}}$ \\
\hline \multirow[t]{2}{*}{$\mathrm{A} \times \mathrm{F}$} & $0,88^{\mathrm{ns}}$ & $1,21^{\mathrm{ns}}$ & $1,15^{\mathrm{ns}}$ & $1,16^{\mathrm{ns}}$ & $1,01^{\mathrm{ns}}$ & $1,36^{\mathrm{ns}}$ \\
\hline & \multicolumn{6}{|c|}{ Estimativas de parâmetros genético-estatísticos } \\
\hline Média & 1,098 & 1,207 & 0,03452 & 0,03023 & 26.154 & 13.964 \\
\hline $\mathrm{CV}(\%)$ & 8,29 & 11,57 & 21,07 & 25,11 & 25,37 & 34,50 \\
\hline $\mathrm{CV}_{\mathrm{P}}$ & - & 2,94 & 7,79 & 6,05 & 7,32 & - \\
\hline $\mathrm{CV}_{\mathrm{Fm}}$ & 2,76 & 5,15 & 13,07 & 10,86 & 11,20 & 13,44 \\
\hline $\mathrm{h}_{\mathrm{m}}^{2}$ & - & 0,33 & 0,36 & 0,31 & 0,43 & - \\
\hline $\mathrm{mg} \mathrm{P}_{2} \mathrm{O}_{5} \mathrm{dm}^{-3}$ solo & \multicolumn{6}{|c|}{ Desempenho médio } \\
\hline 0 & 0,984 & 0,531 & 0,00165 & 0,00055 & 1.617 & 2.119 \\
\hline 200 & 1,083 & 1,299 & 0,04439 & 0,03596 & 38.312 & 22.391 \\
\hline 400 & 1,231 & 1,791 & 0,05761 & 0,05416 & 38.545 & 17.383 \\
\hline
\end{tabular}

** - significativo a $1 \%$ de probabilidade; $* \mathrm{e}^{\text {ns }}$ - significativo e não-significativo a $5 \%$ de probabilidade, respectivamente.

Estimativas dos coeficientes de variação genética $\left(\mathrm{CV}_{\mathrm{p}}\right)$, fenotípica em nível de média de famílias $\left(\mathrm{CV}_{\mathrm{Fm}}\right)$, do coeficiente de variação experimental (CV) e do coeficiente de herdabilidade em nível de média de famílias $\left(\mathrm{h}_{\mathrm{m}}{ }_{\mathrm{m}}\right)$. TPF, CPF e EUPF referem-se ao teor, ao conteúdo e à eficiência de utilização de fósforo nas folhas e TPC, CPC e EUPC correspondem ao teor, ao conteúdo e à eficiência de utilização de fósforo no caule, respectivamente.

Quadro 6 - Teor (g/kg), conteúdo (g) e eficiência e utilização de fósforo (g massa seca $2 / \mathrm{g}$ P) nas folhas e no caule de 18 famílias de meios-irmãos de Eucalyptus grandis, aos 120 dias de idade em casa de vegetação

Table 6 - Concentration $(\mathrm{g} / \mathrm{kg})$, content $(\mathrm{g})$ and efficiency of phosphorus utilization ( $\mathrm{g}$ of dry matter ${ }^{2} / \mathrm{g} P$ ), in the leaves and stem of plants of 18 Eucalytpus grandis half-sib families, 120 days after transplant under greenhouse conditions

\begin{tabular}{|c|c|c|c|c|c|c|}
\hline Família & TPF & TPC & CPF & CPC & EUPF & EUPC \\
\hline 1 & 1,120 & 1,170 & 0,0373 & 0,0297 & 26.595 & 14.096 \\
2 & 1,060 & 1,230 & 0,0354 & 0,0275 & 28.298 & 12.264 \\
3 & 1,095 & 1,220 & 0,0385 & 0,0315 & 29.604 & 13.636 \\
4 & 1,120 & 1,250 & 0,0390 & 0,0298 & 27.686 & 13.205 \\
5 & 1,110 & 1,280 & 0,0333 & 0,0347 & 25.550 & 13.751 \\
6 & 1,120 & 1,170 & 0,0368 & 0,0347 & 26.801 & 14.560 \\
7 & 1,070 & 1,290 & 0,0307 & 0,0332 & 24.424 & 13.667 \\
8 & 1,070 & 1,120 & 0,0280 & 0,0284 & 23.647 & 15.332 \\
9 & 1,120 & 1,140 & 0,0372 & 0,0336 & 28.332 & 17.222 \\
10 & 1,100 & 1,260 & 0,0375 & 0,0299 & 27.715 & 12.913 \\
11 & 1,090 & 1,300 & 0,0367 & 0,0362 & 29.119 & 13.358 \\
12 & 1,120 & 1,170 & 0,0296 & 0,0279 & 20.849 & 16.978 \\
13 & 1,100 & 1,180 & 0,0359 & 0,0283 & 26.249 & 14.718 \\
14 & 1,080 & 1,070 & 0,0314 & 0,0273 & 21.884 & 14.670 \\
15 & 1,110 & 1,230 & 0,0395 & 0,0240 & 31.044 & 10.287 \\
16 & 1,100 & 1,190 & 0,0286 & 0,0263 & 20.978 & 12.468 \\
17 & 1,090 & 1,190 & 0,0313 & 0,0289 & 24.654 & 13.670 \\
18 & 1,070 & 1,170 & 0,0338 & 0,0316 & 27.414 & 14.572 \\
\hline
\end{tabular}

TPF, CPF e EUPF referem-se ao teor, ao conteúdo e à eficiência de utilização de fósforo nas folhas e TPC, CPC e EUPC correspondem ao teor, ao conteúdo e à eficiência de utilização de fósforo no caule, respectivamente. 
PAULA, R.C. et al.

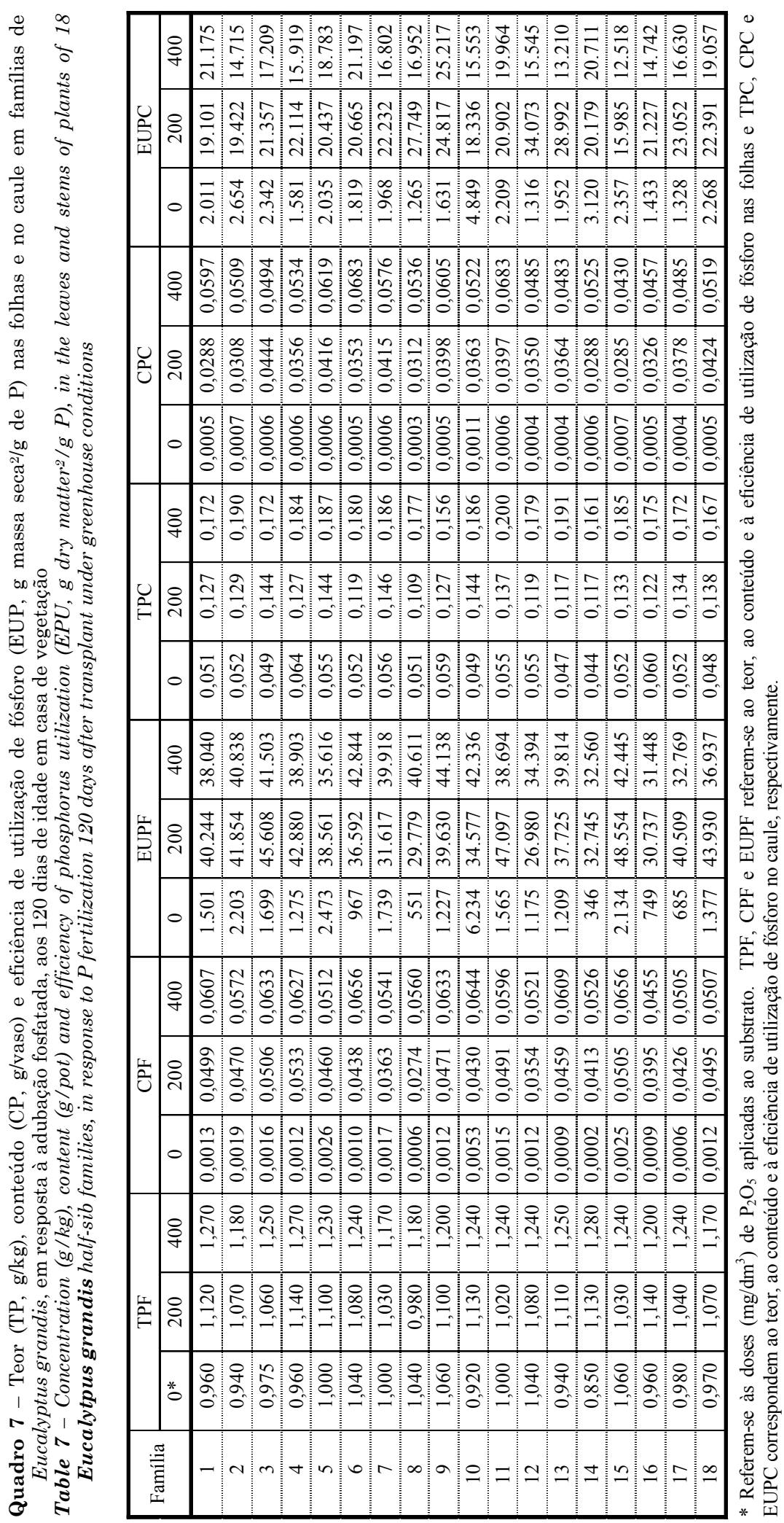


A pequena variação no TPF em relação às doses aplicadas evidencia a ocorrência de um efeito diluição, proporcionado pela maior produção de material vegetal com a aplicação de P. Com a maior produção de biomassa de folhas do que de caule, o efeito de diluição foi mais acentuado nas primeiras. Ainda, é preciso considerar que o P é retranslocado das folhas mais velhas para as mais novas em caso de deficiência, concentrando-se nas folhas que permanecem vivas. Contudo, esses efeitos são minimizados quando a metodologia de Siddiqi \& Glass (1981) é utilizada para o cálculo da eficiência de utilização de nutrientes.

Constatou-se, para todas as famílias, maior teor de $P$ no caule que nas folhas, porém ocorrendo, em geral, o oposto para o conteúdo e para a eficiência de utilização deste nutriente (Quadro 6). Este fato já era esperado, uma vez que nesta fase há maior produção de folhas do que de caule, o que resulta em maiores conteúdos e eficiência de utilização de P neste componente. A diferença porcentual entre as famílias de melhor e de pior desempenho foi de $5,52 \%$ para o TPF, sendo esta diferença mais expressiva para o TPC, $21,88 \%$. Esses valores chegaram a $41,16 \%$ para o $\mathrm{CPF}, 50,33 \%$ para o $\mathrm{CPC}$ e a 47,98 e $67,42 \%$ para a EUPF e para a EUPC, respectivamente, entre as famílias de desempenho superior e inferior.

Os maiores conteúdos de fósforo observados tanto nas folhas quanto no caule, quando foram aplicados $400 \mathrm{mg}$ de $\mathrm{P}_{2} \mathrm{O}_{5}$, não foram acompanhados por maior produção de matéria seca nestes componentes, o que resultou, em última análise, em decréscimo da eficiência de utilização para grande parte das famílias neste nível de adubação em relação à adição de $200 \mathrm{mg}$ de $\mathrm{P}_{2} \mathrm{O}_{5}$ (Quadros 4 e 7). A eficiência de conversão do nutriente em matéria seca foi maior para as folhas do que para o caule, conforme pode ser verificado nestas tabelas.

A família 15, apesar de ter apresentado maiores $\mathrm{CPF}$ e EUPF, foi a que apresentou menores CPC e EUPC, o que ressalta que o comportamento das famílias é variável de acordo com a característica analisada e que dificilmente será encontrada uma família superior para todas as características.

Pelo Quadro 7, pode-se constatar que o comportamento das famílias em relação à adubação fosfatada, independentemente da característica considerada, apresentou o mesmo padrão. De modo geral, os baixos conteúdos de $\mathrm{P}$ nas folhas e no caule, em todas as famílias estudadas, quando da ausência de adubação com P, comprometeram seriamente o crescimento nesta condição.

\section{CONCLUSÕES}

Nas condições em que foi realizado este experimento, pôde-se concluir que:

a) as plantas de eucalipto apresentam grande demanda inicial de fósforo;

b) o teor de fósforo nas folhas não é um bom indicador da suficiência deste elemento no substrato para o crescimento ideal das plantas;

c) foi detectada variabilidade genética entre as famílias apenas para crescimento em altura e em diâmetro e para produção de matéria seca e conteúdo de fósforo nas folhas;

d) as famílias respondem de forma diferenciada aos níveis de adubação fosfatada, para cada característica analisada; e

e) a adição de $200 \mathrm{mg} / \mathrm{dm}^{3}$ de $\mathrm{P}_{2} \mathrm{O}_{5}$, para solos com características semelhantes às do presente experimento, é satisfatória para o bom crescimento e desenvolvimento das plantas, uma vez que o acréscimo nos valores da maioria das características avaliadas foi pequeno quando se comparou a adição de $200 \mathrm{ou}$ $400 \mathrm{mg} / \mathrm{dm}^{3}$ de $\mathrm{P}_{2} \mathrm{O}_{5}$.

\section{AGRADECIMENTO}

À FAPESP (Fundação de Amparo à Pesquisa do Estado de São Paulo), pelo auxílio financeiro a este projeto.

\section{REFERÊNCIAS BIBLIOGRÁFICAS}

ASSOCIATION OF OFFICIAL ANALYTICAL CHEMISTS - A.O.A.C. Official methods of analysis. 12.ed.

Washington, D.C., 1975. 1094 p.

BARROS, N. F.; NOVAIS, R. F.; NEVES, J. C. L. Fertilização e correção do solo para o plantio de eucalipto. In: BARROS, N. F.; NOVAIS, R. F. (Eds.) Relação soloeucalipto. Viçosa, MG: Folha de Viçosa, 1990. p. 127-186.

BRAGA, F. A. et al. Exigências nutricionais de quatro espécies florestais. Revista Árvore, v. 19, n. 1, p. 18-31, 1995.

CLARKSON, D. T. Adaptações morfológicas e fisiológicas das plantas a ambientes de baixa fertilidade. In: ROSAND, P. C. (Ed.) Reciclagem de nutrientes e agricultura de baixos insumos nos trópicos. Ilhéus: CEPLAC/SBCS, 1985. p. $45-75$.

R. Árvore, Viçosa-MG, v.27, n.1, p.25-34, 2003 
PAULA, R.C. et al.

FURTINI NETO, A. E. et al. Eficiência nutricional em mudas de Eucalyptus em relação a fósforo. Revista Árvore, v. 20, n. 1 , p. 17-28, 1996.

GUIMARÃES, H.S. Variabilidade genética para eficiência nutricional em progênies de Eucalyptus camaldulensis e Eucalyptus citriodora. 1993. $68 \mathrm{f}$. Dissertação (Mestrado em Ciência Florestal) - Universidade Federal de Viçosa, Viçosa-MG, 1993.

NAMBIAR, E. K. S.; COTTERILL, P. P.; BOWEN, G. D. Genetic difference in root regeneration of radiata pine. Journal Experimental of Botany, v. 33, n. 132, p. 170-177, 1982.

NOVAIS, R. F.; BARROS, N. F.; NEVES, J. C. L. Nutrição mineral do eucalipto. In: BARROS, N. F.; NOVAIS, R. F. (Eds.) Relação solo-eucalipto. Viçosa, MG: Folha de Viçosa, 1990. p. 25-98.

PAULA, R. C. et al. Estimativas de parâmetros genéticos em famílias de meios-irmãos de Eucalyptus camaldulensis Dehnh. II. Eficiência de utilização de nutrientes. Revista Árvore, v. 20, n. 4, p. 483-493, 1996.
PIMENTEL GOMES, F. Curso de estatística experimental. Piracicaba: Nobel, 1990. 467 p.

RAIJ, B. van, ; CANTARELLA, H.; QUAGGIO, J. A.; FURLANI, A. M. C. Recomendações de adubação e calagem para o Estado de São Paulo. In: RAIJ, B. van; CANTARELLA, H.; QUAGGIO, J. A.; FURLANI, A. M. C. (Eds.) Recomendações de adubação e calagem para o Estado de São Paulo. 2.ed. Campinas: IAC/Fundação IAC, 1997. p. 1-42. (Boletim Técnico, 100)

REIS, G. G. et al. Crescimento e ponto de compensação lumínico em mudas de espécies florestais nativas submetidas a diferentes níveis de sombreamento. Revista Árvore, v. 18, n. 2 , p. 97-106, 1994.

SIDDIQI, M. Y.; GLASS, A. D. M. Utilization index; a modified approach to the estimation and comparison of nutrient utilzation efficiency in plants. Journal Plant Nutrition, v. 4, n. 3, p. 289-302, 1981.

SILVA, H. D.; POGGIANI, F.; COELHO, L. C. Eficiência de utilização de nutrientes em cinco espécies de Eucalyptus. Boletim de Pesquisa Florestal, v. 6/7, p. 1-8, 1983. 